\title{
Substitutes or complements? Diagnosis and treatment with non-conventional and conventional medicine
}

\author{
Aida Isabel Tavares*
}

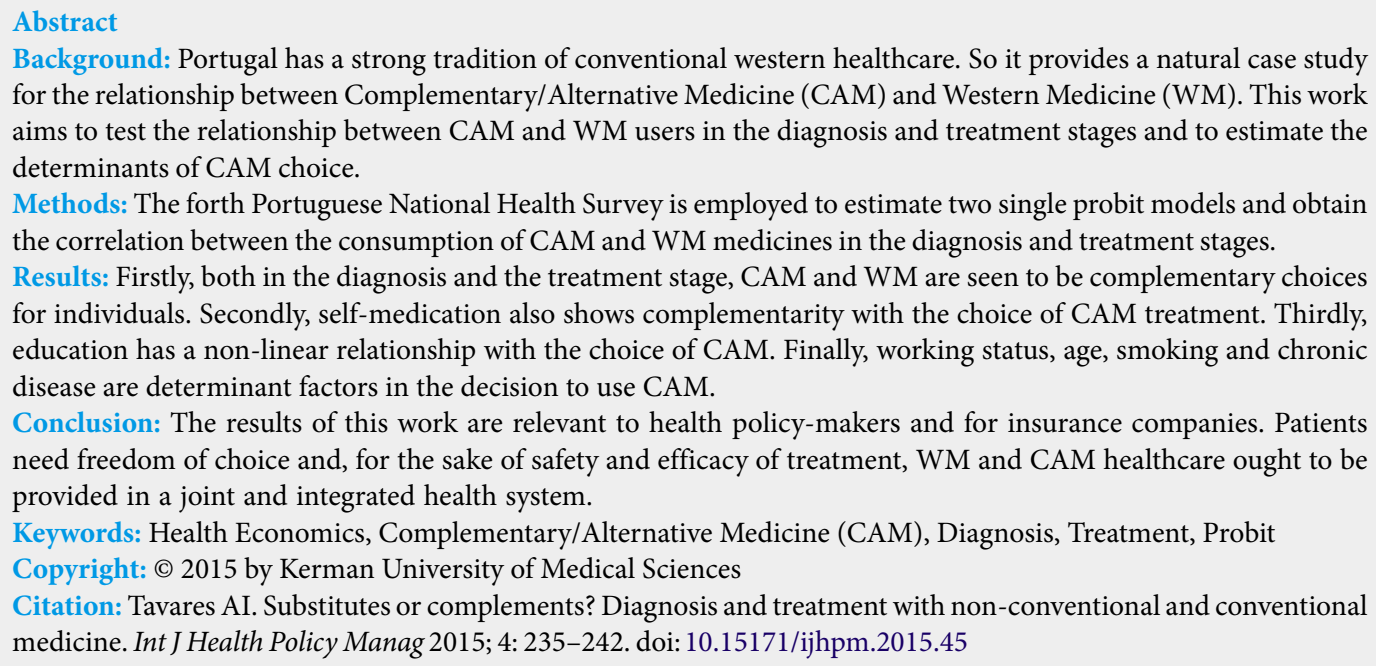

Background: Portugal has a strong tradition of conventional western healthcare. So it provides a natural case study for the relationship between Complementary/Alternative Medicine (CAM) and Western Medicine (WM). This work aims to test the relationship between CAM and WM users in the diagnosis and treatment stages and to estimate the determinants of CAM choice.

Methods: The forth Portuguese National Health Survey is employed to estimate two single probit models and obtain the correlation between the consumption of CAM and WM medicines in the diagnosis and treatment stages.

Results: Firstly, both in the diagnosis and the treatment stage, CAM and WM are seen to be complementary choices for individuals. Secondly, self-medication also shows complementarity with the choice of CAM treatment. Thirdly, education has a non-linear relationship with the choice of CAM. Finally, working status, age, smoking and chronic disease are determinant factors in the decision to use CAM.

Conclusion: The results of this work are relevant to health policy-makers and for insurance companies. Patients need freedom of choice and, for the sake of safety and efficacy of treatment, WM and CAM healthcare ought to be provided in a joint and integrated health system.

Keywords: Health Economics, Complementary/Alternative Medicine (CAM), Diagnosis, Treatment, Probit

Copyright: (C) 2015 by Kerman University of Medical Sciences

Citation: Tavares AI. Substitutes or complements? Diagnosis and treatment with non-conventional and conventional medicine. Int J Health Policy Manag 2015; 4: 235-242. doi: 10.15171/ijhpm.2015.45

Article History:

Received: 9 December 2014 Accepted: 27 February 2015 ePublished: 3 March 2015

\section{*Correspondence to: Aida Isabel Tavares} Email: aitavar@gmail.com

\section{Key Messages}

Implications for policy makers

- Complementary/Alternative Medicine (CAM) and Western Medicine (WM) are complements, both in the diagnosis and treatment stages.

- $\quad$ After a WH diagnosis, people may look for a CAM treatment.

- It is not socially desirable to separate WM from CAM in the NHS.

- Patient empowerment, education and individual characteristics are relevant for the choice of CAM.

Implications for public

Private health insurance providers may exploit the desire of people for access to both Complementary/Alternative Medicine (CAM) and Western Medicine (WM) and explore a niche of this market. Additional research on the relationship between income and the use of CAM is needed. The use of CAM is more frequent than it seems.

\section{Background}

The use of Complementary/Alternative Medicine (CAM) is becoming more and more common. A broad concept of CAM is used here including all modalities of medicine which are not considered conventional, or allopath, Western Medicine (WM). This approach is actually aligned with the definition proposed by World Health Organization (WHO) (1), which accordingly refers to a broad set of healthcare practices that are not part of that country's own tradition and are not integrated into the dominant healthcare system. Examples of CAM in this work include: acupuncture, natural products, herbal care, homeopathy, osteopathy, phytotherapy and chiropractic care. The definition of CAM used here does not distinguish between the different therapeutic medical traditions; they are all given equal consideration as alternatives to allopath medicine. However, this definition is not very different from the one proposed by the European Information Centre for Complementary and Alternative Medicine (2). Accordingly, "the most commonly used CAM therapies in Europe are: homeopathy, phytotherapy, antroposophic medicine, naturopathy, traditional Chinese medicine, osteopathy and chiropractic". Finally, these definitions are also very close to the definitions suggested by the CAMbrella project (3). This project views complementary and alternative medicine as a group of diverse medical and healthcare systems, practices, and products that are not generally considered part of conventional medicine.

Access to and use of CAM has been increasing in Europe since the mid-1980s $(4,5)$. In general, the reasons people use CAM are various and can be summarized as follows: a need for self-empowerment regarding healthcare, a feeling of dissatisfaction with and distrust of WM, and individual values 
and beliefs $(6,7)$. These reasons have been also identified for Portuguese users of CAM (8).

The efficacy and safety of the use of CAM therapies are controversial. On the one hand, the benefits arising from the use of particular CAM therapies are recognized for some diseases such as cancer, asthma, diabetes, cardiovascular diseases, liver diseases and rheumatology (9-12). On the other hand, these benefits lack thorough scientific and clinical evidence (13-15). Moreover, undesirable interactions between CAM and WM treatments are well-known. For instance, the pharmacokinetic interactions between St. John's wort and certain prescribed drugs (16) or between cat's claw and specific blood medication (17) are well-documented. Several research papers review the interaction between herbs, homeopathic and allopathic drugs (18-21). The interactions between traditional Chinese medicines and western therapeutics have been reviewed recently (22).

While acknowledging both the reasons why people choose CAM and also the concern for patient safety and treatment efficacy, the following questions can be raised:

- Are CAM and WM substitutes or complements in the individual decision regarding healthcare?

- How is the relationship between CAM and WM different in the diagnosis and treatment stages?

- What are the main factors determining the individual choice of CAM?

Portugal has a strong tradition of conventional healthcare and so the National Health System does not include any CAM provision. The Portuguese public health system covers the whole population where care is mainly provided without significant copayments, except in the case of drugs [Further details of the Portuguese health system can be found in Barros and Simoes (23)].

Despite this wide coverage, some people choose to buy voluntary private health insurance; it is estimated that around $20 \%$ of the population is covered by private voluntary health insurance $(24)^{1}$.

The total cost of any CAM provision is borne by the individual. Moreover, because of the strong tradition of conventional healthcare, physicians know little about CAM and they do not approve it $(25,26)$. This attitude helps to explain the ignorance people have of CAM and the fact that they do not actively request it. This backdrop means that Portugal provides a natural case study for the relationship between CAM and WM medicines.

This work employs the forth Portuguese National Health Survey, published in 2006. The questions in this survey allow a distinction to be made both between the use of CAM and $\mathrm{WM}$, and also between the diagnosis and the treatment, once some illness symptoms arise.

Two probit models are estimated, reflecting the binary nature of the target and dependent variables showing whether or not CAM was used, while also allowing analysis of the explanatory variables underlying the behaviour of the dependent variables. The probit estimates provide the correlation between the use of CAM and WM.

The theoretical basis for this analysis is the well-known model of demand for health proposed by Grossman (27). Accordingly, factors such as age, income and education are viewed as determinants of the demand for health. The applications of this work are several and they provide the empirical background for the independent variables used in the work presented here (28-31).

A relevant branch of the existing literature is related to the efficacy, safety, and also cost effectiveness of CAM $(32,33)$. There is also some work on the use of CAM for particular diseases and on the attitude of physicians towards CAM $(34,35)$. A systematic review of the literature for a selection of countries is carried out by Harris and Rees (5).

For the case of developing countries, Das and Choudhury (36) determine the socio-economic factors of CAM use and estimate the cost effectiveness of such choice in India. However, they do not study the correlation between the uses of CAM and WM. Van Gameren (37) analyzes the effect of insurance coverage on the use of CAM in Mexico. He finds that CAM is substituted by WM covered by insurance and that higher income households substitute less than lower income households.

The USA is the most studied of all the developed countries. Here, the work of Wolsko et al. (38) is worthy of note, where a study is made of the effect insurance coverage has on the frequency of CAM use, finding a positive correlation. Pagan and Pauly (6) try to understand if the reason people use CAM has more to do with saving money or their personal beliefs. Their results show that people who could not afford WM were more likely to use CAM. Tom Xu and Farrell (39) study the correlation between CAM and WM among racial and ethnic groups in the United States. Their results indicate that the complementarity and substitution of CAM and WM varies depending on the racial and ethnic group and by type of CAM. These are similar to the determinant factors explaining the use of CAM found by other researchers (40). Finally, an older study by Astin (7) looks for the different motives that led people to choose CAM in the USA, but no correlation is made with traditional medicine.

The literature on Europe has been increasing in last few years and concern with CAM in the health systems is flourishing. It is possible to find research work studying nearly every European country while a vast survey was undertaken by the CAMbrella project in 2009-12 $(41,42)$. This project represented a step towards harmonizing existing knowledge and determining the knowledge gaps in this field. The results of the project yielded recommendations for the European Commission and the European Parliament.

European studies of the prevalence of CAM tend to be poor and heterogeneous (43) and also tend to display huge variability in the national regulatory management which makes a comparison across the EU nearly impossible (44). Some of the research published looks at the determinants of the use of CAM in countries like Finland (45), Italy $(46,47)$, Germany (48), Sweden $(49,50)$ and the UK (51). An overview of the results presented by this European research shows that there is a tendency to find common factors explaining the use of CAM; users are more likely to be women, middle aged, well-educated and from higher income brackets and suffering chronic conditions. Nevertheless, no work was found studying the relationship between CAM and WM in general, despite work having been done looking at the relationship for specific conditions such as cancer $(52,53)$ and HIV (54).

Our work tries to fill a gap in the research regarding the 
use of CAM in Southern European countries. Up until now, little work has been done: i) testing the relationship between CAM and WM, where the WM is mainly provided by a National Health System that does not include any CAM, and ii) estimating the determinants of CAM choice. iii) Moreover, as far as the author is aware, no research has been done differentiating CAM from WM in the diagnosis and treatment stages.

The main result of this analysis is that for both cases of diagnosis and treatment CAM and WM are complementary choices for the individual. This result and the other results presented in this work provide a new and broader view concerning the use of CAM in Portugal. As a start point, health policy-makers should take into account the well-being and satisfaction of patients. Not only is this relevant from a safety and efficacy perspective, but also from a standpoint of freedom of choice by individuals. From a market perspective, private health insurance providers may see CAM as a niche to be explored.

\section{Methods}

\section{Data and descriptive statistics}

The data employed is taken from the forth Portuguese National Health Survey (2005/06) providing a representative sample for the country as a whole, since it results from a multi-stage random probability selection design. The survey includes a broad set of questions covering several topics from personal identification to sport and drinking habits. The responses received came from all people in the selected households who accepted to participate. Nationally, $76 \%$ of the selected households agreed to participate; reasons given for non-participation included "nobody resident at that address", "incompatible schedules with interviewers" and "refusal" (the rate of refusal was only 5\%).

Trained interviewers asked the questions and recorded the answers during face-to-face interviews with a household representative or the individual himself.

The working sample covers all 33,770 adults (older than 18), where $47.5 \%$ are males and $52.5 \%$ are females. There are two survey questions that relate to the use of CAM. One question asks about the diagnosis and the other about the treatment after a pre-reported illness or symptoms, as shown in Figure 1. In answering the questions, respondents are obliged to choose one of three answers: "yes", "no" or "do not know". The number of "do not know" answers is insignificant. The relevant questions are presented in the Appendix 1.

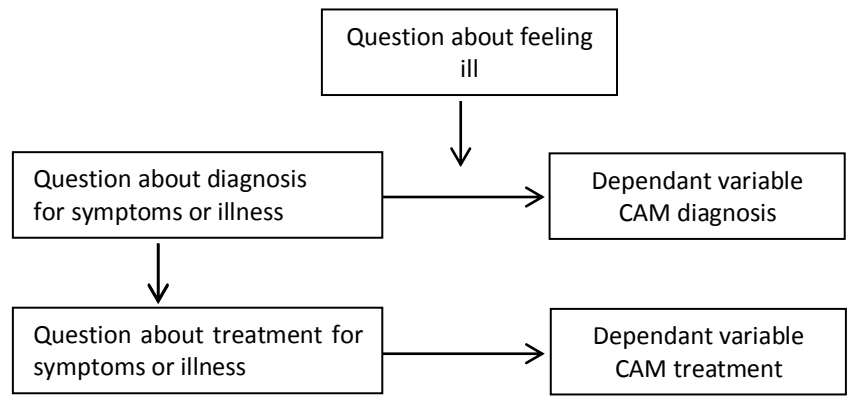

Figure 1. Flowchart for the questions concerning Complementary/ Alternative Medicine (CAM) in the survey
A total of 855 people report using CAM, either in one or both the diagnosis and treatment stages. Table 1 shows the number of users of WM and CAM, according to their choices in the diagnosis and/or treatment stages. It should be noted that it is not possible to sum the numbers presented in Table 1 because there are some people who use CAM purely for diagnosis, other people who use CAM purely for treatment and other people again who use CAM for both diagnosis and treatment. In order to refine the descriptive statistics on the use of CAM and because information on the use of CAM is preceded by information recording a feeling of being ill in the two weeks prior to the survey, we now present some additional statistics on the use of CAM. The supporting structure of the described statistics is presented in Figure 2.

The number of adults reporting "feeling ill" in the two weeks prior to the survey was 5,070 . Table 2 shows that out of this group of 5,070 people, 2,056 looked for a WM professional to get a diagnosis and 68 looked for a CAM diagnosis, while 379 people used a treatment provided by CAM. The total number of people reporting using CAM and feeling ill is 408 . As before, in Table 2, the sum of the entries does not yield the total users of CAM because people use CAM in one or both stages of healthcare.

For those people that sought a WM diagnosis (that is 2,056 people), Table 3 shows the subsequent choice breakdown concerning treatment. Only 649 people followed up from their diagnosis with some form of treatment. From this group, 487 people $(23.7 \%)$ took a WM treatment (usually drugs),

Table 1. Number of users of WM and CAM

\begin{tabular}{lcc}
\hline & WM & CAM \\
\hline Diagnosis & 4,258 & 124 \\
Treatment & 2,598 & 810 \\
\hline
\end{tabular}

$\mathrm{CAM}=$ Complementary/Alternative Medicine; $\mathrm{WM}=$ Western Medicine

People

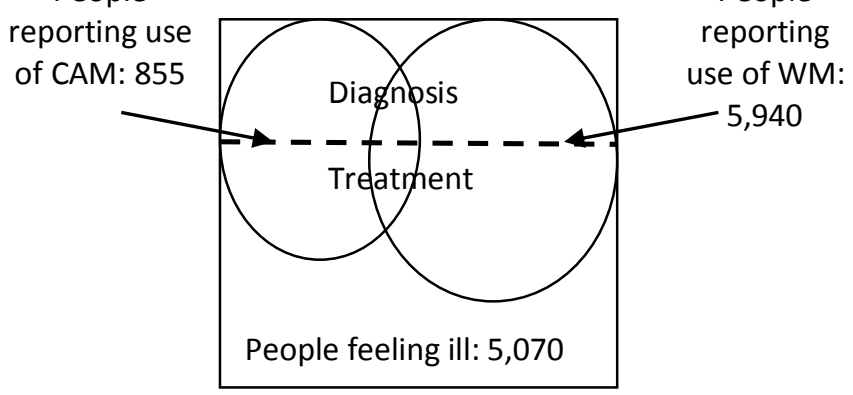

Figure 2. Supporting structure of the additional descriptive statistics

Table 2. Number of users by type of medicine for people reporting "felling ill"a

\begin{tabular}{lcccc}
\hline & \multicolumn{2}{c}{ WM } & \multicolumn{2}{c}{ CAM } \\
\cline { 2 - 5 } & No. of users & $\%$ & No. of users & $\%$ \\
\hline Diagnosis & 2,056 & 40.6 & 68 & 1.3 \\
Treatment & 1,710 & 33.7 & 379 & 7.5 \\
\hline
\end{tabular}

$\mathrm{CAM}=$ Complementary/Alternative Medicine; $\mathrm{WM}=$ Western Medicine

${ }^{a}$ The percentage refers to total numbers of people feeling ill $=5,070$. 
while $162(7.9 \%)$ people decided upon a CAM treatment after the WM diagnosis. These are unexpected numbers because of the divergence in choices between the type of diagnosis and treatment undertaken.

The three most common types of CAM specialist sought for a diagnosis are phytotherapists (27\%), herbal experts (24\%) and acupuncturists (15\%). This pattern of CAM use changes when it comes to treatment, where the three most sought after forms of treatment are herbs and teas (44\%), "other" (33\%) and chiropractic (19\%). No information is available to determine what "other" means, but it can be inferred to include all other CAM which are not on the list of possible choices in the survey, such as, yoga, reiki, cripto therapy and massage.

To uncover more information about the relationships at play, an analysis is made of the correlation between the choices of CAM and WM for treatment and diagnosis (CAMdiagn, CAMtreat, WMdiagn and WMtreat - these variables are binary taking on a value of 1 if the individual reported uses CAM and 0 otherwise). In the next table, the tetrachoric correlations (The tetrachoric correlation is a coefficient computed for two normally distributed binary variables) are shown for the four variables, as well as Cramer's V statistic measuring the association between two binary variables (in brackets).

The values in Table 4 show that the choices of CAM and WM for diagnosis and treatment exhibit in all cases a strong or medium positive correlation. Moreover, they are not strongly associated, that is, each pair of two variables are far from being equal to each other since Cramer's V statistic is very low.

The survey questions supporting the variables relating to the choice of CAM or WM are presented in Appendix 1, along with information on how the variables were created.

\section{Method and model}

The relationship between CAM and WM may be either complement or substitute. These concepts are borrowed

Table 3. Number of users by type of treatment for people reporting being ill and doing WM diagnosis ${ }^{a}$

\begin{tabular}{lcc}
\hline & No. of users & $\%$ \\
\hline WM treatment & 487 & 23.7 \\
CAM treatment & 162 & 7.9 \\
\hline
\end{tabular}

$\mathrm{CAM}=$ Complementary/Alternative Medicine; $\mathrm{WM}=$ Western Medicine .

a Percentage refers to total numbers $=2,056$.

Table 4. Correlations and associations ${ }^{a}$

\begin{tabular}{lllll}
\hline & CAMdiagn & CAMtreat & WMdiagn & WMtreat \\
\hline CAMdiagn & 1 & - & - & - \\
CAMtreat & $\begin{array}{l}0.937 \\
(-0.236)\end{array}$ & 1 & - & - \\
& & & & \\
WMdiagn & 0.694 & 0.729 & 1 & - \\
& $(-0.073)$ & $(-0.211)$ & & \\
WMtreat & 0.588 & 0.439 & 0.533 & 1 \\
& $(-0.056)$ & $(-0.076)$ & $(-0.196)$ & \\
\hline
\end{tabular}

a In brackets the Cramer's V statistic.
Table 5. Independent variables

\begin{tabular}{|c|c|}
\hline Variable & Description \\
\hline \multicolumn{2}{|r|}{ Variables describing social and economic status } \\
\hline Gender & 1 if male; 0 if female \\
\hline Age & Number of years of age \\
\hline Age2 & Square of Age \\
\hline Income & Income per capita ${ }^{a}$ \\
\hline \multicolumn{2}{|r|}{ Variables describing personal status } \\
\hline Single & 1 if single; 0 otherwise \\
\hline Married & 1 if married; 0 otherwise \\
\hline Divorced & 1 if divorced; 0 otherwise \\
\hline Alone & 1 if alone; 0 otherwise \\
\hline \multicolumn{2}{|r|}{ Set of variables describing personal occupation } \\
\hline Work & 1 if works; 0 otherwise \\
\hline Student & 1 if studies; 0 otherwise \\
\hline Unemploy & 1 if unemployed; 0 otherwise \\
\hline Retired & 1 if retired; 0 otherwise \\
\hline \multicolumn{2}{|r|}{ Variables describing health status } \\
\hline Chrndis & $\begin{array}{l}1 \text { if individual has at least one chronic diseaseb; } 0 \\
\text { otherwise }\end{array}$ \\
\hline BMI & Body Mass Index ${ }^{c}$ \\
\hline \multicolumn{2}{|c|}{ Variables describing education and empowerment } \\
\hline Schyr & School years: number of completed schooling years \\
\hline Schyr2 & Square of Schyr \\
\hline Selfmed & $\begin{array}{l}1 \text { if individual chose to take drugs without } \\
\text { conventional doctor prescription; } 0 \text { otherwise }\end{array}$ \\
\hline
\end{tabular}

a Income is computed from the average income of an interval of incomes chosen by respondent, divided by the square of the number of individuals in the family in order to take into account economies of scale.

b The chronic diseases considered are the following: diabetes, asthma, high blood pressure, chronic pain, rheumatism, osteoporosis, glaucoma, retina diseases, cancer, kidney diseases, anxiety, chronic wound, bronchitis, Cerebrovascular Accident (CVA), obesity, depression and heart attack.

${ }^{c} \mathrm{BMI}$ is computed as a ratio between the weight in kilograms and the square of the height in meters.

from the economic theory, in the sense that when the consumption of CAM and WM increases, then they tend to be complementary, but when the consumption of CAM decreases and the WM increases, then they are substitutes. To find the relationship between CAM and WM, two linear equations are estimated, based on several control variables. This econometric approach to test the complementarity of goods and services in health has been used before (55-58). The dependent variables of the econometric model are CAMtreat and CAMdiagn. These are binary variables, taking a value of 1 if the individual reported using CAM and 0 otherwise. The aim to estimate the main determinants of a CAM decision justifies the choice of CAM as a dependent variable.

The independent variables are listed and described in Table 5. For the diagnosis scenario, the estimated probit is as follows:

CAMdiagn $=c_{1}+\alpha_{1} X+\delta_{1}$ WMdiagn $+v_{1}$,

While for the treatment scenario we have:

CAMtreat $=c_{2}+\alpha_{2} X+\delta_{2}$ WMtreat $+\delta_{3}$ CAMdiagn $+\delta_{4}$ $W M$ diagn $+v_{2}$

where $X$ are independent variables, $c_{i}$ is a constant, and $v_{i}$ is the error term, $i=1,2$.

According to the definition of complementarity and substitutability, if the estimated $\delta$ 's are positive, then CAM and $\mathrm{WM}$ are complements; if negative, then CAM and WM are substitutes. 
Another relevant economic estimate concerns the correlation between income and the choice of CAM. If the estimated coefficient is positive, then CAM is a normal good, however, if it is negative, then it is an inferior good.

Finally, the estimated coefficients for the control variables provide information about the correlation each variable has with the choice of CAM, given that all the other variables are constant.

Results

The estimated models are presented in the next table and were obtained with software STATA version 9 (Table 6).

The most relevant result is that CAM and WM are complements, both in the diagnosis and treatment stages, because estimated coefficients are positive and statistical significant.

The second important result is that people, having sought a WM diagnosis, may look for a CAM treatment, as shown in estimated coefficients of model 1 . This result actually shows how CAM and WM are related for patients who seem to value both healthcare contributions. This corroborates previous medical studies that showed the importance of CAM in particular diseases.

Table 6. Results of the estimated models ${ }^{a}$

\begin{tabular}{|c|c|c|c|c|}
\hline & \multicolumn{2}{|c|}{$\begin{array}{c}\text { CAM treatment } \\
\text { Model } 1\end{array}$} & \multicolumn{2}{|c|}{$\begin{array}{c}\text { CAM diagnosis } \\
\text { Model } 2\end{array}$} \\
\hline & Coef. & $P>|z|$ & Coef. & $\mathrm{P}>|\mathrm{z}|$ \\
\hline WMtreat & 0.150 & 0.015 & - & - \\
\hline CAMdiagn & 1.944 & 0.000 & - & - \\
\hline WMdiagn & 0.955 & 0.000 & 0.779 & 0.000 \\
\hline Gender & -0.049 & 0.239 & -0.063 & 0.419 \\
\hline Income & 0.000 & 0.992 & 0.000 & 0.830 \\
\hline Age & 0.019 & 0.013 & 0.043 & 0.005 \\
\hline Age2 & 0.000 & 0.027 & 0.000 & 0.017 \\
\hline Schyr & 0.044 & 0.073 & 0.058 & 0.149 \\
\hline Schyr2 & -0.003 & 0.047 & -0.002 & 0.341 \\
\hline Single & -0.119 & 0.229 & -0.112 & 0.491 \\
\hline Married & -0.176 & 0.036 & -0.233 & 0.084 \\
\hline Widow & -0.125 & 0.240 & -0.349 & 0.081 \\
\hline Work & -0.165 & 0.002 & -0.027 & 0.784 \\
\hline Unemploy & -0.148 & 0.129 & -0.015 & 0.938 \\
\hline Retired & 0.009 & 0.894 & 0.006 & 0.965 \\
\hline Smoke & 0.136 & 0.005 & -0.189 & 0.061 \\
\hline Chrndis & 0.225 & 0.000 & 0.226 & 0.013 \\
\hline BMI & 0.001 & 0.864 & -0.002 & 0.753 \\
\hline Selfmed & 0.278 & 0.000 & 0.644 & 0.000 \\
\hline Cons & -2.916 & 0.000 & -4.236 & 0.000 \\
\hline Number of observation & \multicolumn{2}{|c|}{27,131} & \multicolumn{2}{|c|}{27,131} \\
\hline Wald chi ${ }^{2}$ & \multicolumn{2}{|c|}{1207.680} & \multicolumn{2}{|c|}{283.740} \\
\hline Prob>chi ${ }^{2}$ & \multicolumn{2}{|c|}{0.000} & \multicolumn{2}{|c|}{0.000} \\
\hline Log pseudolikelihood & \multicolumn{2}{|c|}{-2422.211} & \multicolumn{2}{|c|}{-614.351} \\
\hline Pseudo $\mathrm{R}^{2}$ & \multicolumn{2}{|c|}{0.202} & \multicolumn{2}{|c|}{0.161} \\
\hline
\end{tabular}

$\mathrm{BMI}=$ Body mass index

a The non-significant coefficients in regular font; significant coefficients in bold.
The third result worth stressing is that the medical literacy and empowerment of patients, captured by the selfmedication variable, contributes towards choosing CAM. Moreover, this medical literacy and empowerment can also be captured by the existence of chronic disease. These patients tend to understand their condition well, along with what makes them feel better, and they are usually willing to try new approaches to their illness. This is why suffering from at least one chronic disease is a determinant factor in choosing CAM. The other result concerning literacy comes from the significance education holds for the choice of CAM treatment, but not for the CAM diagnosis. The higher the level of education, the more likely it becomes for individuals to choose a CAM treatment. However, the marginal effect on individuals' choice as education increases is negative; education presents an inverted U-shape relationship with CAM treatment.

A somewhat surprising result is that smokers are less likely to look for a CAM diagnosis than a CAM treatment. The descriptive statistics show that 810 smokers use CAM treatments while only 124 smokers use a CAM diagnosis. It is not possible to identify the reasons that encouraged smokers to look for CAM. However, it follows that smoking as a condition does not need a diagnosis, and those wishing to follow programs designed to quit smoking are looking for a CAM treatment and not a diagnosis.

Finally, no significant relationship was found between the choice of CAM and income, leaving us unable to reach a conclusion as to whether CAM represents a normal or inferior good for consumers.

These results obtained here are relevant for health policy matters. Firstly, it may be important for the well-being of patients to have a national health system that integrates both types of medicines. This could help increase the clarity and availability of information for physicians and for patients, and increase communication between them, so that higher efficacy and safety, as well as, access equity could be achieved. Secondly, it may be inferred that there exists an increasing interest in including CAM in private health insurance. While this practice is already current in other European countries, it is now becoming more common in Portugal due to the positive correlation between CAM and WM medicines.

Thirdly, the characterization of those who choose CAM is helpful for policy design. People suffering from chronic diseases, smokers, working and mature adults are those who are more likely to appreciate such health policies.

Finally, it could be argued that the estimation of these two probit models could be done simultaneously, in order to account for possible endogeneity. A bivariate probit was estimated where upon the results were found to be identical to the original estimation. Moreover, no significant correlation was found between the residuals of both probits regressions, which most likely means there is no endogeneity. This can be explained by the strong belief and cultural bias towards conventional medicine in Portugal.

\section{Conclusions and Discussion}

The increasing use of CAM by the Portuguese follows the European trend. The questions raised by this trend are several: Are CAM and WM substitutes or complements in 
the individual decision regarding healthcare? How is the relationship between CAM and WM different in the diagnosis and treatment stages? What are the main factors determining the individual choice of CAM?

The interaction between prescribed WM drugs and CAM therapies is well-known. The importance of this coupled with a concern for the patient's safety, satisfaction and the treatment efficacy, justifies this work.

In this work data is used from the forth Portuguese National Health Survey (2005/06) where two probit models are estimated for CAM diagnosis and treatment. It is found that CAM and WM are complements, both in the diagnosis and treatment stages.

This main result, along with the relevance of patient empowerment and individual patient characteristics, provides important insights for health policy-makers and for private health insurance providers.

The determinant factors of the use of CAM found in this work are not very different from those found in other research work. Some differences arise, as for instance with gender, which is not a significant factor in the current work in contrast with other studies (46-48). Even if no explanation may be provided for this, it is expected that as soon as the prejudice surrounding open discussion of CAM diminishes, gender may be a significant determinant factor driving the choice of CAM.

Income is similarly poor at explaining CAM use. While in other European research $(47,48,51)$, income has had a significant capacity to explain CAM prevalence, here that does not appear to be the case. The reason for this may be due to the way the variable is defined (in classes), meaning it does not capture much of the variability in the use of CAM.

The last difference worth mentioning relates to education. The results found for schooling are inconclusive since the estimated coefficient was significant for CAM treatment but not for CAM diagnosis. This provides a basis for future research as other studies $(46-48,51)$ found a significant relationship and this work finds a negative marginal effect of education on the choice of CAM. This may be interpreted as a decreasing effect of education for very high levels of education.

The results obtained in this work seem to show that the separation between WM and CAM is not socially desirable. Patients need for freedom of choice and, for the sake of safety and efficacy of treatment, WM and CAM healthcare should be provided in a joint and integrated health system.

From a different perspective, private health insurance providers may exploit the desire of people for access to both WM and CAM and explore a niche of this market. In particular, advertising such health insurance to mature working adults who tend to smoke more often.

The main disadvantage of this analysis is the number of people self-reporting using CAM. This number may be smaller than the true number of people using CAM diagnosis and treatment. This under-reporting can be explained by the fact that Portuguese society is WM dominated and CAM is little known or understood, leading people to not openly discuss its use. Hence, one potential limitation arises from the fact that it is not possible to interpret what is the meaning of negative answers to the survey questions used to create the observable variables on use of CAM. Does it mean "no use of CAM"? Or does it mean "I do not want to talk about it"? Lastly, the economic quantitative analysis and the database used in this work does not allow for a qualitative analysis where cultural, social and anthropological features also play a role. The emphasis of the work presented here has quantitative nature.

\section{Ethical issues}

Ethical principles were followed throughout the conduct of this research. Informed consent was obtained from each respondent and their anonymity guaranteed.

Competing interests

Author declares that she has no competing interests.

Author's contribution

AIT is the single author of the manuscript.

\section{Endnotes}

This work was done before the full effects of the debt crisis took hold in 2011. At that time, the National Health Service (NHS) copayments were fairly low. In 2010 , it was estimated that on average about $30 \%$ of total expenditure on healthcare was private, mainly in the form of out-of-pocket (OOP) payments. After 2011, some reforms have been implemented in order to decrease public expenditure on health (25). However, an assessment of these measures has not been made. Moreover, due to financial constraints, there is no statistical information about the current use of CAM nor is there any health survey.

\section{References}

1. World Health Organization (WHO). Traditional medicines: definitions [internet]. [cited 30 January 2014]. Available from: http://www.who.int/medicines/areas/traditional/definitions/ en/

2. European Information Centre for Complementary and Alternative Medicine (EICAM). 2008. [cited 30 June 2013]. Available from: http://www.eiccam.eu/portal.html

3. CAMbrella Project. CAMbrella project funded by the 7th Framework Programme of the European Commission (FP7HEALTH-2009-3.1-3) [internet]. [cited 31 January 2015]. Available from: http://www.cambrella.eu/home.php

4. Fisher P, Ward A. Complementary Medicine in Europe. BMJ 1994; 309: 107-11. doi: 10.1136/bmj.309.6947.107

5. Harris $P$, Rees $R$. The prevalence of complementary and alternative medicine use among the general population: a systematic review of the literature. Complement Ther Med 2000; 8: 88-96. doi: 10.1054/ctim.2000.0353

6. Pagán JA, Pauly MV. Access to conventional medical care and the use of complementary and alternative medicine. Health Affairs 2005; 24: 255-62. doi: 10.1377/hlthaff.24.1.255

7. Astin JA.Why patients use alternative medicine: results of a national study. JAMA 1998; 20: 279: 1548-53. doi: 10.1001/ jama.279.19.1548

8. Silva BA. Optar pelo uso de terapias alternativas e complementares: representações sociais da Medicina Alternativa e/ou Complementar e da Medicina Oficial/Convencional [master thesis in Social Psicology]. Oporto, Portugal: Faculty of Psychology and Educational Sciences, University of Oporto; 2008.

9. Akinci AC, Zengin N, Yildiz H, Sener E, Gunaydin B. The complementary and alternative medicine use among asthma and chronic obstructive pulmonary disease patients in the southern region of Turkey. Int J Nurs Pract 2011; 17: 571-82. doi: 10.1111/j.1440-172x.2011.01976.x

10. Houssen ME, Ragab A, Mesbah A, El-Samanoudy AZ, Othman 
G, Moustafa AF, et al. Natural anti-inflammatory products and leukotriene inhibitors as complementary therapy for bronchial asthma. Clin Biochem 2010; 43: 887-90. doi: 10.1016/j. clinbiochem.2010.04.061

11. Beuth J, van Leendert R, Schneider B, Uhlenbruck G. Reduced side-effects of adjuvant hormone therapy in breast cancer patients by complementary medicine. In Vivo 2010; 24: 799-802.

12. Nahas R, Moher M. Complementary and alternative medicine for the treatment of type 2 diabetes. Can Fam Physician 2009; 55: 591-96.

13. Langhorst J, Wulfert $H$, Lauche $R$, Klose $P$, Cramer $H$, Dobos GJ, et al. Systematic Review of Complementary and Alternative Medicine Treatments in Inflammatory Bowel Diseases. J Crohns Colitis 2015; 9: 86-106. doi: 10.1093/ecco-jcc/jju007

14. De Silva V, El-Metwally A, Ernst E, Lewith G, Macfarlane GJ. Evidence for the efficacy of complementary and alternative medicines in the management of fibromyalgia: a systematic review. Rheumatology (Oxford) 2010; 49: 1063-8. doi: 10.1093/ rheumatology/keq025

15. Furlan AD, Yazdi F, Tsertsvadze A, Gross A, Van Tulder $M$, Santaguida $L$, et al. Complementary and alternative therapies for back pain II. AHRQ Publication No. 10(11)-E007, Agency for Healthcare Research and Quality U.S. Department of Health and Human Services. Evid Rep Technol Assess (Full Rep) 2010; 194: 1-764.

16. Zhou S, Chan E, Pan SQ, Huang M, Lee EJ. Pharmacokinetic of interactions of drugs with St.John's wort. J Psychopharmacol 2004; 18: 262-76. doi: 10.1177/0269881104042632

17. Rispler DT, Sara J. Impact of complementary and alternative treatment modalities on the care of orthopaedic patients. J Am Acad Orthop Surg 2011; 19: 634-43.

18. Woodward KN. The potential impact of the use of homeopathic and herbal remedies on monitoring the safety of prescription products. Hum Exp Toxicol 2005; 24: 219-33. doi: 10.1191/0960327105ht529oa

19. Hu Z, Yang X, Ho PC, Chan SY, Heng PW, Chan E, et al. Herbdrug interactions: a literature review. Drugs 2005; 65: 1239-82. doi: 10.2165/00003495-200565090-00005

20. Ulbricht C, Chao W, Costa D, Rusie-Seamon E, Weissner W, Woods J. Clinical evidence of herb-drug interactions: a systematic review by the natural standard research collaboration. Curr Drug Metab 2008; 9: 1063-120. doi: 10.2165/00003495200565090-00005

21. Fugh-Berman A. Herb-drug interactions. Lancet 2000; 355: 1348. doi: 10.1016/s0140-6736(99)06457-0

22. Chan E, Tan M, Xin J, Sudarsanam S, Johnson DE. Interactions between traditional Chinese medicines and Western therapeutics. Curr Opin Drug Discov Devel2010; 13: 50-65.

23. Barros PP, Simoes J. Portugal: Health system review. Health Syst Transit 2011; 13: 1-156.

24. Simões J. Essay Series: Healthcare system in Portugal [internet]. Medical Solutions. [cited 20th August 2012]. Available from: http://www.siemens.com/healthcare-magazine

25. Miranda, AS. Terapêuticas não convencionais: Perspectivas dos médicos de medicina geral e familiar [master thesis in Medicine]. Covilha, Portugal; Faculty of Health Sciences, University of Beira Interior; 2010.

26. Antunes JL. A Profissão de Médico. Análise Social 2003; XXXVIII: 77-99.

27. Grossman M. On the concept of health capital and the demand for health. J Polit Econ 1972; 80: 403-20. doi: 10.1086/259880

28. Belloc NB, Breslow L. Relationship of physical health status and health practices. Prev Med 1972; 1: 409-21. doi: 10.1016/00917435(72)90014-x

29. Breslow L, Enstrom J. Persistence of health habits and their relationship to mortality. Prev Med 1980; 9: 469-83. doi:
10.1016/0091-7435(80)90042-0

30. Schoenborn CA. Health habits of US adults, 1985: the Alameda Seven revisited. Public Health Reports 1986; 101: 571-80.

31. Kenkel D. Should we eat breakfast. Health Econ 1995; 4: 15-29. doi: 10.1002/hec.4730040103

32. Zhao XF, Du Y, Liu PG, Wang S. Acupuncture for stroke: evidence of effectiveness, safety, and cost from systematic reviews. Top Stroke Rehabil 2012; 19: 226-33. doi: 10.1310/ tsr1903-226

33. Marchisio P, Bianchini S, Galeone C, Baggi E, Rossi E, Albertario G, et al. Use of complementary and alternative medicine in children with recurrent acute otitis media in Italy. Int J Immunopathol Pharmacol 2011; 24: 441-9.

34. Kooreman $P$, Baars EW. Patients whose GP knows complementary medicine tend to have lower costs and live longer. European Journal Health Economics 2012; 13: 769-76. doi: 10.1007/s10198-011-0330-2

35. Shuval JT, Gross R, Ashkenazi Y, Schachter L. Integrating CAM and Biomedicine in Primary care settings, physicians perspectives on boundaries and boundary work. Qual Health Res 2012; 22: 1317-29. doi: 10.1177/1049732312450326

36. Das T, Choudhury D. Are complementary and alternative medicines alternative to conventional medical system? An economic evaluation. Applied Economic Letters 2007; 14: 697 700. doi: 10.1080/13504850600592580

37. van Gameren E. Health insurance and use of alternative medicine in Mexico. Health Policy 2010; 98: 50-7. doi: 10.1016/j. healthpol.2010.04.006

38. Wolsko PM, Eisenberg DM, Davis RB, Ettner SL, Phillips RS. Insurance coverage, medical conditions, and visits to alternative medicine providers, results of a national survey. Arch Intern Med 2002; 162: 281-7. doi: 10.1001/archinte.162.3.281

39. Tom Xu K, Farrell TW. The Complementarity and substitution between unconventional and mainstream medicine among racial and ethnic groups in the United States. Health Serv Res 2007; 42: 811-26. doi: 10.1111/j.1475-6773.2006.00628.x

40. Chan YM, Huang $\mathrm{H}$, Mei $\mathrm{H}$. Socioeconomic status, attitudes on use of health information, preventive behaviours, and complementary and alternative medical therapies: using a US national representative sample. Natural and Applied Sciences Part / 2012; 3: 15-23.

41. Eardley S, Bishop FL, Prescott P, Cardini F, Brinkhaus B, SantosRey K, et al. Final Report of CAMbrella Work Package 4 CAM use in Europe - The patients' perspective. Part I: A systematic literature review of CAM prevalence in the EU [internet]. CAMbrella project funded by the 7th Framework Programme of the European Commission (FP7-HEALTH-2009-3.1-3), 2012. [cited 31 January 2015]. Available from: http://phaidra.univie. ac.at/

42. Nissen $\mathrm{N}$, Johannessen $\mathrm{H}$, Schunder-Tatzber $\mathrm{S}$, Lazarus $\mathrm{A}$, Weidenhammer W. Final Report of CAMbrella Work Package 3 Citizens' needs and attitudes towards CAM [internet]. CAMbrella project funded by the 7th Framework Programme of the European Commission (FP7-HEALTH-2009-3.1-3), 2012. [cited 31 January 2015]. Available from: http://phaidra.univie.ac.at/

43. Eardley S, Bishop FL, Prescott P, Cardini F, Brinkhaus B, SantosRey K, et al. A Systematic Literature Review of Complementary and Alternative Medicine Prevalence in EU. Forsch Komplementmed 2012; 19: 18-28. doi: 10.1159/000342708

44. von Ammon K, Frei-Erb M, Cardini F, Daig U, Dragan S, Hegyi $\mathrm{G}$, et al. Complementary and alternative medicine provision in Europe - first results approaching reality in an unclear field of practices. Forsch Komplementmed 2012; 19: 37-43. doi: 10.1159/000343129

45. Hämeen-Anttila KP, Niskala UR, Siponen SM, Ahonen RS. The use of complementary and alternative medicine products 
in preceding two days among Finnish parents - a population survey. BMC Complement Altern Med 2011; 11: 107-14. doi: 10.1186/1472-6882-11-107

46. Giannelli M, Cuttini M, Arniani S, Baldi P, Buiatti E. Nonconventional medicine in Tuscany: attitudes and use in the population. Epidemiology Prevenzione 2004; 28: 27-33.

47. Barbadoro P, D'Errico MM, Minelli A, Pennacchietti L, Ponzio E. Complementary and alternative medicine (CAM) among adults in Italy: use and related satisfaction. Eur J Integr Med 2011; 3: e325-32. doi: 10.1016/j.eujim.2011.09.001

48. Bücker B, Groenewold M, Schoefer Y, Schäfer T. The use of complementary alternative medicine (CAM in 1001 German adults: results of a population based telephone survey. Gesundheitswesen 2008; 70: e29-36. doi: 10.1055/s-20081081505

49. Al-Windi A, Elmfeldt D, Svärdsudd K. The relationship between age, gender, well-being and symptom and the use of pharmaceuticals, herbal medicines and self-care products in a Swedish municipality. Eur J Clin Pharmacol 2000; 56: 311-7. doi: 10.1055/s-2008-1081505

50. Al-Windi A. Determinants of complementary and alternative medicine (CAM) use. Complement Ther Med 2004; 12: 99-111. doi: 10.1016/j.ctim.2004.09.007

51. Thomas K, Coleman P. Use of complementary and alternative medicine in general population in Great Britain. Results from the
National Omnibus survey. J Public Health (Oxf) 2004; 26: 152-7. doi: 10.1093/pubmed/fdh139

52. Adams J, Easthope G, Sibbritt D. Exploring the relationship between women's health and the use of complementary and alternative medicine. Complement Ther Med 2003; 11: 156-8. doi: 10.1016/s0965-2299(03)00062-1

53. Colebunders R, Dreezen C, Florence E, Pelgrom Y, Schrooten W; Eurosupport Study Group. The use of complementary and alternative medicine by persons with HIV infection in Europe. Int $\mathrm{J}$ STD AIDS 2003; 14: 672-4. doi: 10.1258/095646203322387929

54. Molassiotis A, ScottJA, Kearney N, PudD, Magri M, Selvekerova $\mathrm{S}$, et al. Complementary and alternative medicine use in breast cancer patients in Europe. Support. Care Cancer 2006; 14: 2607. doi: $10.1258 / 095646203322387929$

55. Decker SL. Cigarettes and alcohol: substitutes or complements? NBER Working Paper, WP/7535, Cambridge; 2000.

56. Ganz ML. Family Health effects: complements or substitutes. Health Econ 2001; 10: 699-714. doi: 10.1002/hec.612

57. Rask K, Rask K. Delivering public health care services: substitutes, complements or both? Contemp Econ Policy 2005; 23: 28-39. doi: 10.1093/cep/byi003

58. Atella V, Deb P. Are primary care physicians, public and private sector specialists substitutes or complements? Evidence from a simultaneous equations model for count data. $J$ Health Econ 2008; 27: 770-85. doi: 10.1016/j.jhealeco.2007.10.006

\author{
Appendix 1 \\ I) Question for Diagnosis Stage \\ "Related to that (health) problem you mentioned before, to whom \\ did you go?" \\ 1) Doctor \\ 2) Nurse \\ 3) Pharmacist \\ 4) Acupuncturist \\ 5) Homeopaths \\ 6) Osteopaths \\ 7) Naturopaths \\ 8) Phytotheraphist \\ 9) Chiropractor \\ 10) Herbal expert \\ 11) Healer \\ 12) Other health professional \\ Variable CAMdiagn is created by at least one answer being chosen \\ from options 4 to 10. \\ Variable WMdiagn is created by at least one answer being chosen \\ from options 1 to 3 .
}

II) Question for Treatment Stage

"In relation to the (health) problem you mentioned before, what treatment have you administered in the last two weeks?"

1) Herbs and teas

2) Change of food

3) Took drugs you knew

4) Took drugs advised by friends

5) Took drugs advised by doctor

6) Acupuncture

7) Homeopathy

8) Osteopathy

9) Naturapathy

10) Phytotherapy

11) Chiropractic

12) Something else

Variable CAMtreat is created by at least one answer being chosen out of theoptions 1 and 6 to 11 .

Variable WMtreat is created by at least one answer being chosen from options 3 to 5 . 